CRUZ, Paulo Márcio; BARBIERO, Victória Faria. Aspectos gerais dos precedentes judiciais e a dogmática do novo código de processo civil. Revista Eletrônica Direito e Política, Programa de PósGraduação Stricto Sensu em Ciência Jurídica da UNIVALI, Itajaí, v.15, n.3, 30 quadrimestre de 2020. Disponível em: www.univali.br/direitoepolitica - ISSN 1980-7791

\title{
ASPECTOS GERAIS DOS PRECEDENTES JUDICIAIS E A DOGMÁTICA DO NOVO CÓDIGO DE PROCESSO CIVIL
}

\author{
GENERAL ASPECTS OF JUDICIAL PRECEDENTS AND THE DOGMATICS OF \\ THE NEW CIVIL PROCEDURE CODE
}

\author{
Paulo Márcio Cruz ${ }^{1}$ \\ Victória Faria Barbiero
}

\begin{abstract}
RESUMO
A presente pesquisa tem o objetivo de fazer um paralelo entre os precedentes judiciais da common law e como estes são inseridos no contexto brasileiro. Para isso, faz-se uma análise dos elementos constitutivos e práticos dos precedentes judiciais no sistema common law, como também a perspectiva histórica que culminou seu surgimento. Ademais, verifica-se os novos enquadramentos judiciários e atividades do juiz a partir dessa nova lógica vinculante no direito processual brasileiro. O precedente se torna um instrumento adequado para resolver os problemas de duração dos processos judicias e segurança jurídica do judiciário, e sua efetividade só poderá ser medida com a sua prática.
\end{abstract}

PALAVRAS-CHAVE: Common law; Precedentes judiciais; Processo Civil.

\begin{abstract}
This research aims to make a parallel between the common law judicial precedents and how they are inserted in the Brazilian context. For this, an analysis is made of the constitutive and practical elements of judicial precedents in the common law system, as well as the historical perspective that culminated in its emergence. Moreover, the new judicial frameworks and activities of the judge are verified from this new binding logic in Brazilian procedural law. The precedent becomes an appropriate instrument for solving the problems of length of judicial proceedings and legal certainty of the judiciary, and its effectiveness can only be measured with its practice.
\end{abstract}

KEYWORDS: Judicial precedents; Common law; Procedural law.

\footnotetext{
${ }^{1}$ Pós-Doutor em Direito do Estado pela Universidade de Alicante, na Espanha, Doutor em Direito do Estado pela Universidade Federal de Santa Catarina e Mestre em Instituições Jurídico-Políticas também pela Universidade Federal de Santa Catarina - UFSC. Coordenador e professor do Programa de Pós-Graduação Stricto Sensu em Ciência Jurídica da Universidade do Vale do Itajaí UNIVALI em seus cursos de Doutorado e Mestrado em Ciência Jurídica. Foi Secretário de Estado em Santa Catarina e Vice-reitor da UNIVALI. É professor visitante nas universidades de Alicante, na Espanha, e de Perugia, na Itália. (pcruz@univali.br).

2 Mestranda em Jurisdição Constitucional e Democracia pelo Programa de Pós-Graduação Stricto Sensu em Direito, da Universidade de Passo Fundo. Bolsista CAPES/CNPq. E-mail: 142281@upf.br.
} 
CRUZ, Paulo Márcio; BARBIERO, Victória Faria. Aspectos gerais dos precedentes judiciais e a dogmática do novo código de processo civil. Revista Eletrônica Direito e Política, Programa de PósGraduação Stricto Sensu em Ciência Jurídica da UNIVALI, Itajaí, v.15, n.3, 30 quadrimestre de 2020. Disponível em: www.univali.br/direitoepolitica - ISSN 1980-7791

\section{INTRODUÇÃO}

A partir do marco procedimentalista do Estado de democrático de direito, no qual o processo se torna uma garantia processual, mecanismo de eficácia dos direitos fundamentais, a decisão judicial fundamentada não possui apenas uma função endoprocessual, como também possibilita o controle do exercício do Poder Judiciário pelo povo, assegurando o princípio democrático de direito, além da solução intersubjetiva do conflito pelas partes demandantes.

Estudar o direito é especialmente analisar suas fontes e formas das quais as normas jurídicas surgem. $O$ direito é a ciência que dispõe o conjunto de normas que regulam as relações sociais e possui formatações distintas referentes às questões culturais que influenciam suas tradições legais. Dentre esses sistemas, é na Common Law que surgiu a fonte formal de direito objeto deste presente trabalho, o precedente judicial. Tendo em vista o surgimento do precedente judicial como um dos novos instrumentos do Código de Processo Civil brasileiro, verifica-se a importância de sua análise para fora de uma tradição jurídica estritamente common law.

Para isso, em um primeiro momento, faz-se uma análise das bases do sistema em que surgiu o precedente judicial, a fim de demonstrar quais seriam circunstâncias históricas e bases sociais que embasaram o instrumento. $\mathrm{Na}$ segunda parte, pretende-se demonstrar os elementos da sistemática dos precedentes, como a ratio decidendi, dicta e distinguishing na doutrina consolidada do common law.

Por fim, verifica-se o contexto que o precedente judicial vinculante foi inserido no código de processo civil brasileiro, bem como quais são seus impactos imediatos nessa nova maneira argumentativa incorporada no judiciário, e os novos espaços ocupados pelos juízes. Ademais, verifica-se que os precedentes pretendem diminuir a morosidade processual e garantir a segurança jurídica das decisões brasileiras, o que torna o Poder Judiciário mais sustentável em meio às crises advindas do capitalismo predatório. 
CRUZ, Paulo Márcio; BARBIERO, Victória Faria. Aspectos gerais dos precedentes judiciais e a dogmática do novo código de processo civil. Revista Eletrônica Direito e Política, Programa de PósGraduação Stricto Sensu em Ciência Jurídica da UNIVALI, Itajaí, v.15, n.3, 30 quadrimestre de 2020. Disponível em: www.univali.br/direitoepolitica - ISSN 1980-7791

\section{ELEMENTOS HISTÓRICOS E CONSTITUTIVOS DA COMMON LAW}

A common law constitui-se em uma família de direitos à qual pertence o sistema jurídico instituído em países como os Estados Unidos e a Inglaterra, em contraste da tradição civil law, que é a base de países que fundamentam um direito na cultura romano-germânica, como, por exemplo, o Brasil. O histórico apego dos ingleses pela tradição ${ }^{3}$ deu azo ao surgimento dessa concepção jurídica também conhecida como direito costumeiro, por exprimir essencialmente a tradição em suas normativas basilares. Essa é uma diferença sensível do jurista inglês em relação ao civil law, pois, a preferência em evidenciar e valorizar a continuidade histórica da lógica jurídica no common law, é distinto do caráter mais racional e pragmático da norma no sistema romano-germânico ${ }^{4}$.

As origens do sistema em análise aludem à conquista da Inglaterra pelos normandos, ainda no ano de 1066. Este é um fato importante na história do direito inglês, tendo em vista que a ocupação estrangeira proporcionou a centralização do governo baseado em uma unidade administrativa rígida e forte. As tradições tribais decaem e surge o feudalismo, a centralização da justiça toma forma por meio de cortes de justiça que, inicialmente, dispunham de costumes locais para construírem as suas decisões. Porém, gradualmente consolidou-se um sistema de direito comum a todo o Reino Inglês, daí decorrente a nomenclatura common law ${ }^{5}$.

O direito aos cidadãos era de obra exclusiva dos Tribunais Reais de Justiça (que vulgarmente eram chamados de Tribunais de Westminster) e, excepcionalmente, quando os que não ficavam conformados com a decisão poderiam ainda recorrer ao monarca para a reforma do entendimento das cortes, se fosse o caso. Gradativamente, a procura pela reconsideração aumentou e a medida necessária foi indicar um Conselheiro do Rei (chanceler) que atuava como a "consciência" do rei, possibilitando decisões discordantes dos Tribunais da Common Law, em

\footnotetext{
${ }^{3}$ PORTO, Sérgio Gilberto. Sobre a common law, civil law e o precedente judicial: estudos de Direito Processual Civil em homenagem ao Professor Egas Dirceu Moniz de Aragão. São Paulo: RT, 2005. p. 2.

${ }^{4}$ DAVID, René. Os grandes sistemas do direito contemporâneo. São Paulo: Martins Fontes, 2002. p. 330.

5 DAVID, René. Os grandes sistemas do direito contemporâneo. p. 332 - 333.
} 
CRUZ, Paulo Márcio; BARBIERO, Victória Faria. Aspectos gerais dos precedentes judiciais e a dogmática do novo código de processo civil. Revista Eletrônica Direito e Política, Programa de PósGraduação Stricto Sensu em Ciência Jurídica da UNIVALI, Itajaí, v.15, n.3, 30 quadrimestre de 2020. Disponível em: www.univali.br/direitoepolitica - ISSN 1980-7791

nome da justiça. Esse sistema foi chamado de equity ${ }^{6}$, e seus tribunais, Courts of Chancery ${ }^{7}$.

O excesso de formalismo na common law, que foi o meio empregado pelos teóricos a fim de perpetuar a segurança jurídica do sistema, incentivou o surgimento da ideia de um direito com o intuito de barrar o excesso de injustiças causadas pela rigidez exacerbada, principalmente após a sua grande expansão no século XIII ${ }^{8}$.

[...] A Equity não pode ser traduzida por equidade, pura e simplesmente. São normas que se superpõem ao Common Law. A Equity origina-se de um pedido das partes da intervenção do rei em uma contenda que decidia de acordo com os imperativos de sua consciência. Tem por escopo suprimir as lacunas e complementar o Common Law? ${ }^{9}$

O campo processual da equidade surgiu por meio de writs, ações judiciais sob forma das ordens dadas pelo rei ou de seus Chancelers. Nesse sistema, não bastava apenas o direito material para a solução da controvérsia, mas também era crucial utilizar-se do writ cabível no caso determinado, ou seja, utilizar-se de um remédio processual adequado - é daí que decorre a expressão remedies precede rights ${ }^{10} 11$.

Em um primeiro momento, os antigos chancelers eram Cléricos que tentavam inserir na equity os preceitos do Direito Canônico, e utilizavam suas consciências como fonte declarada das decisões. Com a reforma anglicana do Henrique VIII, juristas tomaram o posto e utilizavam-se do direito Romano, de forma que as

\footnotetext{
${ }^{6}$ No português, equidade.

7 BARBOZA, Estefânia Maria de Queiroz. Precedentes judiciais e segurança jurídica: fundamentos e possibilidades para a jurisdição constitucional brasileira. São Paulo: Editora Saraiva, 2014. p. 29.

8 PORTO, Sérgio Gilberto. Sobre a common law, civil law e o precedente judicial: estudos de Direito Processual Civil em homenagem ao Professor Egas Dirceu Moniz de Aragão. p. 4.

${ }^{9}$ VENOSA, Sílvio de Salvo. Direito civil: parte geral. 3a ed. São Paulo: Atlas, 2003.

${ }^{10} \mathrm{Na}$ tradução literal ao português, remédios precedem os direitos. A concepção decorre de uma ideia que o processo, ou seja, o formalismo processual é mais importante que o direito, enquanto norma.

11 BARBOZA, Estefânia Maria de Queiroz. Precedentes judiciais e segurança jurídica: fundamentos e possibilidades para a jurisdição constitucional brasileira. p. 30.
} 
CRUZ, Paulo Márcio; BARBIERO, Victória Faria. Aspectos gerais dos precedentes judiciais e a dogmática do novo código de processo civil. Revista Eletrônica Direito e Política, Programa de PósGraduação Stricto Sensu em Ciência Jurídica da UNIVALI, Itajaí, v.15, n.3, 30 quadrimestre de 2020. Disponível em: www.univali.br/direitoepolitica - ISSN 1980-7791

ideias tornaram-se aos poucos mais sistematizadas ${ }^{12}$, aplicando-se teses de forma corretiva ou supletiva as decisões dos Tribunais Reais. A equity era escrita e secreta, enquanto a common law era oral e pública ${ }^{13}$.

Como remete Radbruch ${ }^{14}$, no início do século XIX, a grande reforma judiciária de 1873 uniu a Court of Chancery aos Tribunais da Common Law graças ao LordChanceler da Inglaterra, Lord Eldon. Sua visão da equity como uma forma de Case Law - um conjunto de precedentes - incentivou uma organização judiciária uniforme, consubstanciada em um direito costumeiro e rígido. A equity, por sua vez, foi vencida exatamente pelo motivo que foi criada: a segurança jurídica. Esse contexto histórico esclarece o dualismo do direito inglês (common Law em sentido lato), sendo que ambas as formas de solução de conflitos subsistem, mesmo que unificados, e os tribunais podem aplicar por vezes a common law em sentido estrito, por vezes a equity, que complementa e aperfeiçoa o primeiro.

No ordenamento jurídico inglês, a segurança jurídica é uma ideia predominante que sustenta e reforça a estabilidade da própria ciência jurídica, não ficando a cargo de opiniões esparsas, ao ser perceptível de forma clara e indubitável. A vinculação ao precedente propõe um Direito sem instabilidade de decisão que possui um sistema normativo predominantemente baseado em mandamentos gerais e abstratos. Essa concepção de direito só foi possível, inicialmente, com o autocontrole, que é uma característica específica da magistratura na Inglaterra e principalmente do povo inglês como um todo ${ }^{15}$.

É oportuno lembrar que o juiz sempre esteve ao lado do parlamento na luta contra o arbítrio do rei, prezando pela tutela dos direitos e das liberdades do cidadão. Assim, não houve desconfiança por parte da população ou medo de que o Judiciário posicionar-se a favor do absolutismo. O juiz inglês não só interpretava a lei, como extraia direitos e deveres, a partir do common law,

\footnotetext{
12 RADBRUCH, Gustav. O espírito do direito inglês e a jurisprudência Anglo-Americana. Rio de Janeiro: Lumen Juris, 2010. p. 54.

13 BARBOZA, Estefânia Maria de Queiroz. Precedentes judiciais e segurança jurídica: fundamentos e possibilidades para a jurisdição constitucional brasileira. p. 31.

${ }^{14}$ RADBRUCH, Gustav. O espírito do direito inglês e a jurisprudência Anglo-Americana. p. 54-55.

${ }^{15}$ RADBRUCH, Gustav. O espírito do direito inglês e a jurisprudência Anglo-Americana. p. 59.
} 
CRUZ, Paulo Márcio; BARBIERO, Victória Faria. Aspectos gerais dos precedentes judiciais e a dogmática do novo código de processo civil. Revista Eletrônica Direito e Política, Programa de PósGraduação Stricto Sensu em Ciência Jurídica da UNIVALI, Itajaí, v.15, n.3, 30 quadrimestre de 2020. Disponível em: www.univali.br/direitoepolitica - ISSN 1980-7791

diferentemente do que ocorreu na positivação do direito romano-germânico, em face da Revolução Francesa ${ }^{16}$.

Os juristas ingleses concebem o direito como essencialmente jurisprudencial (case law), sendo que as regras do direito inglês são, fundamentalmente, a razão das decisões proferidas pelo tribunais superiores da Inglaterra, ou seja, o reconhecimento da autoridade dos precedentes. Dessa forma, a regra no common law é mais específica posto que a decisão só pode ser reproduzida se conhecido detalhadamente os elementos que compõem o litígio e os motivos que ela foi afirmada (questão que será melhor esmiuçada na segunda parte). Em comparação, o sistema de civil law maneja um enunciado - constituído pelo legislador ou pela doutrina - que é apto a conduzir os cidadãos em uma generalidade de casos, sem uma relação obrigatória a um litígio em particular ${ }^{17}$.

Ao dizer que o direito inglês tem como principal influência a jurisprudência, atribui-se extrema importância ao papel do criador - que é o juiz. Além da relação de autoridade às decisões já tomadas pelo Judiciário, o sistema é primordialmente prático, pragmático e casuístico, já que a função do juiz é aplicar a justiça, e não seguir uma regra pré-estabelecida. É um sistema aberto, pois apenas encontra-se a solução da divergência a posteriori, sendo as normas reinterpretadas e estabelecidas continuamente. No civil law, para cada caso presume-se que haverá uma tese aplicável, assim percebemos um sistema fechado $^{18}$.

Cumpre salientar que a forte influência histórica na consolidação do sistema common law bem como a inexistência de um direito doutrinário e dogmatizado nas universidade inglesas, fez este direito surgir de uma prática judiciária cotidiana, e não de maneira científica como acontece com no civil law. Antes mesmo de vi à tona o precedente, o juiz já decidia de forma casuística - valia-se

\footnotetext{
16 MARINONI, Luiz Guilherme. Aproximação crítica entre as jurisdições de civil law e de common law e a necessidade de respeito aos precedentes no Brasil. Revista da Faculdade de Direito UFPR, v. 49, p. 11-58. 2009. p. 19.

17 DAVID, René. Os grandes sistemas do direito contemporâneo. p. 379.

18 BARBOZA, Estefânia Maria de Queiroz. Precedentes judiciais e segurança jurídica: fundamentos e possibilidades para a jurisdição constitucional brasileira. p.31.
} 
CRUZ, Paulo Márcio; BARBIERO, Victória Faria. Aspectos gerais dos precedentes judiciais e a dogmática do novo código de processo civil. Revista Eletrônica Direito e Política, Programa de PósGraduação Stricto Sensu em Ciência Jurídica da UNIVALI, Itajaí, v.15, n.3, 30 quadrimestre de 2020. Disponível em: www.univali.br/direitoepolitica - ISSN 1980-7791

de decisões anteriores para embasar as seguintes, sem constituírem-se verdadeiros precedentes ${ }^{19}$.

Foi necessário buscar um caminho para o common law entre a ideia normativa do direito natural e os fatos empírico dos costumes sociais. O commow law foi fundado segundo um discurso racional nos quais os juízes, guiados pela coerência ou harmonia da razão no direito, aplicavam às máximas do direito às infinitas diversidades das questões humanas que lhes eram confrontadas. Assim, o common law moderno emergiu de uma confluência de costumes antigos, direito natural e razão jurídica ${ }^{20}$.

O direito inglês não é imune às normas postadas fora do Poder Judiciário, criadas por um legislador, a chamada Statue Law. Essas normas são mandamentos de exceção, já que a regra é o direito criado pelo juiz (jude make law), e que a partir da constatação de uma lacuna, utiliza-se da lei escrita ${ }^{21}$. Há o princípio da supremacia do Parlamento na Inglaterra, que é a característica constitucional do parlamento a revogar ou elaborar qualquer lei, porém, sempre obedecendo aos limites da common law ${ }^{22}$.

Reitera-se que o common law é considerado um direito não escrito, no sentido de que não pressupõe a existência de um texto positivo. As regras do direito estariam contidas nas decisões já publicadas pelos tribunais, mas não necessariamente ordenadas em legislações positivas ${ }^{23}$.

Se no direito inglês primitivo havia baixa produção de leis, isso não ocorre no common law contemporâneo. A suposição de que em países que seguem o sistema de direito common law a produção legislativa é baixa, não condiz com a realidade, como, por exemplo, há estados dos Estados Unidos que possuem

\footnotetext{
${ }_{19}$ ABBOUD, Georges. STRECK, Lenio Luiz. O Que é Isto?: O Precedente Judicial e as Súmulas Vinculantes. São Paulo: Livraria do Advogado Editora, 2015. p. 43.

20 BARBOZA, Estefânia Maria de Queiroz. Precedentes judiciais e segurança jurídica: fundamentos e possibilidades para a jurisdição constitucional brasileira. p. 34.

${ }^{21}$ SOARES, Guido Fernando Silva. Common law: introdução ao direito dos EUA. São Paulo: Revista dos Tribunais, 1999. p. 37-39.

22 BARBOZA, Estefânia Maria de Queiroz. Precedentes judiciais e segurança jurídica: fundamentos e possibilidades para a jurisdição constitucional brasileira. p.32 - 37.

23 BARBOZA, Estefânia Maria de Queiroz. Precedentes judiciais e segurança jurídica: fundamentos e possibilidades para a jurisdição constitucional brasileira. p.32.
} 
CRUZ, Paulo Márcio; BARBIERO, Victória Faria. Aspectos gerais dos precedentes judiciais e a dogmática do novo código de processo civil. Revista Eletrônica Direito e Política, Programa de PósGraduação Stricto Sensu em Ciência Jurídica da UNIVALI, Itajaí, v.15, n.3, 30 quadrimestre de 2020. Disponível em: www.univali.br/direitoepolitica - ISSN 1980-7791

tantas leis quanto em países que adotam a civil law ${ }^{24}$. Aliás, nos EUA, em que pese há uma grande influência inglesa, o seu direito foi construído de uma forma peculiar: a) Statue Law tem uma posição de criação de direito mais vinculante do que na Inglaterra; b) há a presença marcante da Constituição Federal com força maior que qualquer outra norma, e dos direitos humanos fundamentais; c) não adotaram a ideia do princípio da supremacia do parlamento, sendo que a constituição detém a autoridade suprema; d) fala-se em uma aproximação com o sistema civil law ${ }^{25}$.

Assim, atualmente, a common law é a base dos sistemas jurídicos da Inglaterra, Irlanda do Norte, Irlanda, do País de Gales, dos Estados Unidos, Canadá, Austrália, Nova Zelândia, Paquistão, Singapura, Hong Kong, África do Sul, Índia, Malásia, Brunei e diversos outros países normalmente de língua inglesa, ou colonizados pela Inglaterra ainda no imperialismo. No próximo tópico far-se-á uma análise da posição do precedente vinculante no common law, assim como de sua lógica hermenêutica.

\section{A DOUTRINA DO StARE DECISIS ET NON QUIETA MOVERE E A HERMENÊUTICA DOS PRECEDENTES NA COMMON LAW}

A teoria do stare decisis relaciona-se com o brocardo latino stare decisis et non quieta movere (respeitar as coisas decididas e não mexer no que está estabelecido), e significa não admitir a possibilidade de ignorar as decisões anteriores já resolvidas por um juízo. Trata-se de uma teoria típica de países que seguem a autoridade do precedente, e advêm, sobretudo, para dar segurança às relações jurídicas atribuindo igualdade e coerência ao direito. Todavia, o common law não se confunde com o stare decisis, uma vez que este surgiu após à consolidação do sistema, sendo apenas um de seus efeitos modernos ${ }^{26}$.

\footnotetext{
24 MARINONI, Luiz Guilherme. Aproximação crítica entre as jurisdições de civil law e de common law e a necessidade de respeito aos precedentes no Brasil. p. 19.

25 SOARES, Guido Fernando Silva. Common law: introdução ao direito dos EUA. p. 42.

26 MARINONI, Luiz Guilherme. Aproximação crítica entre as jurisdições de civil law e de common law e a necessidade de respeito aos precedentes no Brasil. p. 18.
} 
CRUZ, Paulo Márcio; BARBIERO, Victória Faria. Aspectos gerais dos precedentes judiciais e a dogmática do novo código de processo civil. Revista Eletrônica Direito e Política, Programa de PósGraduação Stricto Sensu em Ciência Jurídica da UNIVALI, Itajaí, v.15, n.3, 30 quadrimestre de 2020. Disponível em: www.univali.br/direitoepolitica - ISSN 1980-7791

Nesse sentido,

A doutrina dos precedentes se estruturou no final do século XVII, a partir de uma mudança no método filosófico que orientava o pensamento da época. Essa mudança deve-se ao método experimental de Robert Boyle, que se contrapôs ao cientificismo de Thomas Hobbes. A obra de Boyle influenciou a filosofia do direito de Matthew Hale, para qual a validade dos princípios legais, tais como os princípios das ciências naturais, depende da repetição e de verificação e validação dos membros da comunidade. Assim, afirma que, por muitos séculos, a lei do Ocidente desenvolvida historicamente, com cada geração formando-se conscientemente na experiência de seus predecessores, era um fato conhecido ${ }^{27}$.

O stare decisis é justamente a doutrina que atribui à eficácia vinculante ao precedente, e este, por sua vez, constitui-se como fonte de direito da common law. O precedente é, por definição, um evento passado que serve como um guia para uma ação presente. Entender o precedente é fundamentalmente compreender como esses eventos podem ser conectados. Quando decide-se utilizando por base um precedente, é considerado significativo o fato que a situação foi anteriormente abordada, porém a decisão feita não será seguida necessariamente por aquilo que ela nos ensina, mas sim por sua força vinculante, mesmo que haja fundamentos para não aplicá-la ${ }^{28}$.

Schauer $^{29}$ argumenta que "today's conscientious decision-makers are obliged to decide not only today's case, but tomorrow's as well"30, assim, o precedente envolve uma responsabilidade especial que permite decidir 0 futuro. Diversamente do que ocorre com a jurisprudência nos sistemas de civil law, apenas um único precedente é capaz de construir direito e vincular obrigações. Logo, nos sistemas de common law o precedente é tido como vinculante.

A lógica dos precedentes subsiste em obedecer a uma decisão anterior unicamente pelo seu status de decisão de um tribunal superior ou de decisão

27 ABbOUD, Georges. STRECK, Lenio Luiz. O Que é Isto?: O Precedente Judicial e as Súmulas Vinculantes. p. 42.

${ }^{28}$ DUXBURY, Neil. The nature and authority of precedent. Cambridge University Press, 2008. p. $1-3$.

${ }^{29}$ DUXBURY, Neil. The nature and authority of precedent. p. 4.

30 Nossa tradução: "Os conscientes tomadores de decisões de hoje são obrigados a decidir não apenas os casos de agora, mas os de amanhã também". 
CRUZ, Paulo Márcio; BARBIERO, Victória Faria. Aspectos gerais dos precedentes judiciais e a dogmática do novo código de processo civil. Revista Eletrônica Direito e Política, Programa de PósGraduação Stricto Sensu em Ciência Jurídica da UNIVALI, Itajaí, v.15, n.3, 30 quadrimestre de 2020. Disponível em: www.univali.br/direitoepolitica - ISSN 1980-7791

passada no mesmo âmbito da competência jurisdicional. Em relação ao precedente vertical, essa vinculação não é nada além de um modelo de autoridade hierárquica dentro de um sistema jurídico, em que tribunais superiores têm o poder de vincular suas decisões aos tribunais que são inferiores. Quanto ao precedente horizontal, espera-se que tribunais sigam suas próprias decisões, sendo uma forma de hierarquia artificial imposta às decisões anteriores e as atuais, a decisão anterior se torna superior pelo simples fato da anterioridade ${ }^{31}$.

Não há de ser desconsiderado que nenhum caso é idêntico, mas, também, se fosse negado toda e qualquer semelhança, o direito estaria sempre se reiniciando repetidamente como se nenhum julgamento existisse. A continuidade do direito exerce um papel de integridade de interpretação e segurança jurídica no sistema de stare decisis ${ }^{32}$. Para isso, a teoria dos precedentes possui uma série de conceitos específicos que conduzem a busca pelos motivos que determinam a vinculação das decisões e são temas de difícil definição mesmo em países com tradição common law.

Encontrar a ratio decidendi de uma decisão judicial é importante porque é ela que vai criar um precedente à decisão subsequente. A ratio nada mais é que a parte impositiva de uma decisão que enuncia a razão ou o fundamento da questão definida perante a corte, o porquê o tribunal resolver daquela maneira. A decisão completa é a que adquire força entre as partes de um processo, mas a ratio decidendi é vinculante a todos ${ }^{33}$.

Veja-se os seguinte exemplo: No caso (1) MacPherson v. Buick Motor Company, o juiz decidiu que o fabricante de automóveis de passeio Buick Motor Company, seria responsável por danos causados ao comprador pelas rodas defeituosas fabricadas em outra companhia, mas incorporadas pela Buick na fabricação de seus automóveis, apesar da ausência de liame contratual. No caso (2), Donoghue v. Stevenson, a consumidora estava em um café, e, ao servir-se pela

\footnotetext{
${ }^{31}$ SCHAUER, Frederick. Thinking like a lawyer: a new introduction to legal reasoning. p. 37.

32 RAMIRES, Mauricio. Crítica à aplicação de precedentes no direito brasileiro. Porto Alegre: Livraria do Advogado, 2010. p.73.

33 BARBOZA, Estefânia Maria de Queiroz. Precedentes judiciais e segurança jurídica: fundamentos e possibilidades para a jurisdição constitucional brasileira. p. 185.
} 
CRUZ, Paulo Márcio; BARBIERO, Victória Faria. Aspectos gerais dos precedentes judiciais e a dogmática do novo código de processo civil. Revista Eletrônica Direito e Política, Programa de PósGraduação Stricto Sensu em Ciência Jurídica da UNIVALI, Itajaí, v.15, n.3, 30 quadrimestre de 2020. Disponível em: www.univali.br/direitoepolitica - ISSN 1980-7791

segunda vez de cerveja de gengibre, percebe que da garrafa saiu também pedaços de caramujo morto. Apesar de que os casos à primeira vista não serem similares, já que carros são diferentes de cerveja de gengibre, cada um é vendido em estabelecimentos diferentes, e não possuem os mesmos valores de mercado, eles têm em comum o fato de serem transações de consumo, e em ambos os casos um defeito não aparente causou dano ou mal-estar. Para isso, precisamos saber não apenas o que o tribunal decidiu, mas também por que o tribunal decidiu daquela forma, para, de fato, descobrir se é um precedente válido ${ }^{34}$.

Marinoni ${ }^{35}$ ressalta que não basta olhar apenas a parte dispositiva de uma decisão para chegar a um precedente, já que a razão de decidir encontra-se essencialmente na fundamentação, mesmo que nela não se confunda. Goodhart, no importante ensaio que introduz o seu método de identificação dos precedentes, propõe que a ratio decidendi deve ser determinada a partir dos fatos dados como materiais (material facts) e selecionados como importantes pelo o juiz, bem como, da análise realizada da decisão do precedente. É interessante a teoria explanada pelo autor já que decorre da escolha de fatos essenciais dadas pela decisão do juiz, assim criando o direito. Portanto, é nesta análise que deve ser encontrada a razão de decidir.

Goodhart $^{36}$ ainda expõe que o juiz determina um verdadeiro princípio de direito quando delimita a ratio decidendi, ao restringir quais são os fatos relevantes e irrelevantes para uma decisão. Porém, não é sempre que esses fatos são expressamente denominados quanto a sua relevância pelo julgador, se tornando difícil a delimitação da ratio. Para isso, deve-se considerar que os fatos omitidos são presumidamente imateriais/irrelevantes.

Duxbury explica que a teoria de Goodhart em nenhum momento exclui a relevância da fundamentação do juiz para a identificação dos precedentes, mas,

\footnotetext{
${ }^{34}$ SCHAUER, Frederick. Thinking like a lawyer: a new introduction to legal reasoning. Boston: Harvard University Press, 2009. p. 39.

35 MARINONI, Luiz Guilherme. Precedentes Obrigatórios. p. 162-165.

${ }^{36}$ GOODHART, Arthur L. Determining the ratio decidendi of a case. Yale Lj, v. 40, p. 161, 1930. p. 175-176.
} 
CRUZ, Paulo Márcio; BARBIERO, Victória Faria. Aspectos gerais dos precedentes judiciais e a dogmática do novo código de processo civil. Revista Eletrônica Direito e Política, Programa de PósGraduação Stricto Sensu em Ciência Jurídica da UNIVALI, Itajaí, v.15, n.3, 30 quadrimestre de 2020. Disponível em: www.univali.br/direitoepolitica - ISSN 1980-7791

estes fundamentos possuem a peculiar importância de servir como um guia para determinar quais fatos são materiais ou imateriais ${ }^{37}$.

Outro detalhe importante para se analisar na doutrina do stare decisis é a Obiter Dictum. A parte da sentença considerada desnecessária para a solução do caso concreto, ou o argumento não aprovado pela maioria dos juízes, é conhecido por obiter dictum - uma expressão latina que significa "algo dito de passagem". Esse enunciado não possui os efeitos vinculantes, ou seja, não compõe a ratio decidendi e não podem ser invocados como precedente na decisão de casos sucessivos. Normalmente designadas pela forma abreviada dicta, é algo extra, podendo ser observações do juiz, conclusões sobre fatos irrelevantes, ou explicações abrangentes de uma área do direito ${ }^{38}$. Além disso, cabe ressaltar que - Poder Judiciário deve respeitar o princípio da inércia da jurisdição e da congruência, portanto a delimitação do dicta não permite que a decisão de um caso resolva toda e qualquer questão relacionada ao objeto da demanda, mas, tão-somente a questão que foi provocada pelas partes. Portanto a dicta previne que uma decisão frágil e sem um verdadeiro contraditório exercido seja capaz de adquirir a autoridade de um precedente ${ }^{39}$.

Inicialmente, no século XIX era comum o entendimento de que a dicta não poderia ser um raciocínio judicial (judicial opinion), tendo apenas um caráter extrajudicial ${ }^{40}$. Conclui Duxbury ${ }^{41}$ que a:

Ratio Decidendi can mean either "reason for the decision" or "reason for deciding". It should not be inferred from this that the ratio decidendi of a case must be the judicial reasoning. Judicial reasoning may be integral to the ratio, but the ratio itself is more than the reasoning, and within many cases

\footnotetext{
37 DUXBURY, Neil. The nature and authority of precedent. p. 82-82.

38 SCHAUER, Frederick. Thinking like a lawyer: a new introduction to legal reasoning. Boston: Harvard University Press, 2009. p. 37.

39 MELLO, Patrícia Perrone Campos; BARROSO, Luís Roberto. Trabalhando com uma nova lógica: a ascensão dos precedentes no direito brasileiro. Revista da AGU, v. 15, n. 3, p. 9-52, 2016. p. 2325.

40 MARINONI, Luiz Guilherme. Precedentes Obrigatórios. São Paulo: Revista dos Tribunais, 2016. p. 169.

${ }^{41}$ DUXBURY, Neil. The nature and authority of precedent. p. 68
} 
CRUZ, Paulo Márcio; BARBIERO, Victória Faria. Aspectos gerais dos precedentes judiciais e a dogmática do novo código de processo civil. Revista Eletrônica Direito e Política, Programa de PósGraduação Stricto Sensu em Ciência Jurídica da UNIVALI, Itajaí, v.15, n.3, 30 quadrimestre de 2020. Disponível em: www.univali.br/direitoepolitica - ISSN 1980-7791

there will be judicial reasoning that constitutes not part of the ratio, but obiter dicta ${ }^{42}$.

Logo, manifesta-se novamente a necessidade basilar de descoberta da ratio decidendi visto que ambos os conceitos são diretamente atrelados. De acordo com Duxbury ${ }^{43}$, teóricos teriam tentado implementar a ideia do holding, que, por definição, seria a regra jurídica que aplicada aos fatos do caso específico geraria o resultado. Porém, a tradicional divisão de ratio-dicta ainda é a mais difundida.

Ao passo de que busca-se as semelhanças capazes de vincular uma decisão a outra subsequente, há técnicas argumentativas, por parte de juízes ou advogados, que pretendem desconsiderar um precedente com a finalidade de não aplicá-lo em uma decisão posterior. Entre elas, estão o distinguishing e o overruling.

A ideia de distinguishing é que em um exame inicial a ratio decidendi da ação nova seria semelhante a da anterior, mas, pela argumentação das partes, o juiz percebe que trata-se de uma discussão jurídica distinta com a presença de fatos peculiares. Distinguishing significa, portanto, a distinção entre os casos por meio da não compatibilidade de ratio, dando ensejo ao juiz deixar de aplicar o precedente ${ }^{44}$.

O precedente manifesta sua autoridade e força mesmo quando o juiz deixa segui-lo, pois ao fundamentar a decisão deverá demonstrar justificativas pela falta de motivos materiais que não ensejam a vinculação dos casos. Percebe-se que a distinção é uma atividade do juiz no processo de decidir, e, segundo Barboza45 "deve ser de tal maneira que demonstre motivação suficiente convincente para se abster de seguir uma decisão anterior".

\footnotetext{
42 Nossa tradução:"A ratio decidendi pode significar tanto 'razão para a decisão', como 'razão para decidir'. Não se deve inferir disso que a ratio decidendi de um caso deve ser um raciocínio judicial. O raciocínio jurídico pode integrar a ratio, mas a ratio em si mesma é mais que o raciocínio, e no interior de vários casos vai haver raciocínios judiciais que não constituem parte da ratio, mas da obiter dicta"

${ }^{43}$ DUXBURY, Neil. The nature and authority of precedent. p. 68.

44 MELLO, Patrícia Perrone Campos; BARROSO, Luís Roberto. Trabalhando com uma nova lógica: a ascensão dos precedentes no direito brasileiro. p. 26.

45 BARBOZA, Estefânia Maria de Queiroz. Precedentes judiciais e segurança jurídica: fundamentos e possibilidades para a jurisdição constitucional brasileira. p. 194.
} 
CRUZ, Paulo Márcio; BARBIERO, Victória Faria. Aspectos gerais dos precedentes judiciais e a dogmática do novo código de processo civil. Revista Eletrônica Direito e Política, Programa de PósGraduação Stricto Sensu em Ciência Jurídica da UNIVALI, Itajaí, v.15, n.3, 30 quadrimestre de 2020. Disponível em: www.univali.br/direitoepolitica - ISSN 1980-7791

O overruling significa, em linhas gerais, ultrapassar/revogar o entendimento de um precedente pelo tribunal, seja pois o tribunal não considera como correto o entendimento de um precedente ou o contexto social passou por uma mudança e tal preceito não se encaixa mais nos conceitos morais da contemporaneidade. À vista disso, overruling é um modo de substituir um precedente por um novo, negando a aplicação da uniformização da doutrina stare decisis. É considerada uma atividade judicial mais radical no sistema; e possui um caráter de controle em vezes que a discricionariedade de decidir do jurisdicionado é considerado inapropriado, portanto tem um importante sentido de reconfirmar o direito permitindo que um precedente seja aplicado apenas quando há um propósito de justiça ${ }^{46}$.

Barboza $^{47}$ sobressalta que as razões que ensejam a não aplicação de um precedente são relevantes para inserir uma responsabilidade sensível em congruência à diversidade local, já que uma grande crítica em relação à teoria uniforme do precedente vinculante é exatamente a perpetuação de ratio injustas -seja por sua falta de utilidade ou mudança de realidade social- que reproduzem decisões também injustas.

Não há como negar a importância que o stare decisis teve para o common law e seu desenvolvimento ao longo dos séculos, nem mesmo, esquecer que o precedente constitui-se como a principal fonte de direito do sistema. Por isso, é fundamental a análise realizada preliminarmente a adentrar a dogmática adotada pelo legislador brasileiro.

\section{O PROCESSO DE "COMMONLIZAÇÃO" DO DIREITO BRASILEIRO E A INCORPORAÇÃO DOS PRECEDENTES JUDICIAIS VINCULANTES PARA UM JUDICIÁRIO SUSTENTÁVEL}

As mudanças sociais e tecnológicas dessa nova era que está começando fizeram com que as sociedades se tornassem hipercomplexas, iniciando um processo de aumento significativo do número de litígios que chegam ao Poder Judiciário.

46 BARBOZA, Estefânia Maria de Queiroz. Precedentes judiciais e segurança jurídica: fundamentos e possibilidades para a jurisdição constitucional brasileira. p.196-197.

47 BARBOZA, Estefânia Maria de Queiroz. Precedentes judiciais e segurança jurídica: fundamentos e possibilidades para a jurisdição constitucional brasileira. p. 191. 
CRUZ, Paulo Márcio; BARBIERO, Victória Faria. Aspectos gerais dos precedentes judiciais e a dogmática do novo código de processo civil. Revista Eletrônica Direito e Política, Programa de PósGraduação Stricto Sensu em Ciência Jurídica da UNIVALI, Itajaí, v.15, n.3, 30 quadrimestre de 2020. Disponível em: www.univali.br/direitoepolitica - ISSN 1980-7791

Desse modo, a sociedade hipercomplexa representa um novo e profundo desafio para a jurisdição, demandando uma forma diferente de racionalizar o direito, ao encarar fatos não antes vistos. Em tempos de abarrotamento do aparato judicial, morosidade processual e falta de acesso ao judiciário, surge o desafio de se fazer "justiça" de um modo justo e rápido, que não cause mais demoras e sofrimento por parte do cidadão, afinal o judiciário é um dos grandes garantidores dos direitos fundamentais.

A grande complexidade das relações sociais modernas, e como consequência, a busca pela solução da lide sociológica no âmbito do Poder Judiciário, traz a importância de estudos dos pilares da jurisdição brasileira, frente à busca pelo devido processo legal e efetivação dos direitos fundamentais nas decisões tomadas pelos magistrados.

No tocante a essas mudanças, o Poder Judiciário passa a exercer um papel de protagonismo, e, conforme Bodnar; Cruz:

Com a velocidade imposta pela comunicação digital via internet, o que Rifkin chama de civilização empática foi e vai se formando. A base do raciocínio moderno perde força gradualmente e vai dando lugar a valores superlativos, muito diferentes de liberdade, liberalismo, capitalismo, direito de propriedade, entre tantos outros. Começam a surgir discussões muito sérias em torno de temas até então negligenciados pelos axiomas modernos. Com isso, o "tempo" do direito e do estado faz com que suas estruturas se tornem cada vez mais anacrônicas e, por isso, incapazes de dar respostas minimamente eficientes às sociedades globalizadas conectadas. É nesse ambiente que surgiu, na última década do século $X X$, o que se convencionou chamar de ativismo judicial, o qual começou a transformar 0 processo de produção do direito, tradicionalmente realizado a partir dos parlamentos, tendo a lei como fonte primária ${ }^{48}$.

O ativismo judicial fez com que ocorresse a judicialização de funções até então tidas como típicas dos outros poderes do Estado. Este fenômeno já vinha dando um intenso protagonismo ao Poder Judiciário e fazendo com que a Civil Law se aproximasse da Common Law, em um processo gradativo de emparelhamento dessas famílias de direito.

48 BODNAR, Zenildo; CRUZ, Paulo Márcio. A commolização do direito positivo, o ativismo judicial e a crise do estado. Novos Estudos Jurídicos, v. 21, n. 3, p. 1332-1351, 2016. p. 1341-1343. 
CRUZ, Paulo Márcio; BARBIERO, Victória Faria. Aspectos gerais dos precedentes judiciais e a dogmática do novo código de processo civil. Revista Eletrônica Direito e Política, Programa de PósGraduação Stricto Sensu em Ciência Jurídica da UNIVALI, Itajaí, v.15, n.3, 30 quadrimestre de 2020. Disponível em: www.univali.br/direitoepolitica - ISSN 1980-7791

Para tanto, tendo em vista o problema de insegurança jurídica causada pela imprevisibilidade das decisões judiciais proferidas para dar conta dos inúmeros processos, os precedentes vinculantes foram incorporados no Código de Processo Civil de 2015 com o objetivo de trazer a integridade das decisões judiciais, capaz de garantir maior previsibilidade, segurança do direito e estabilidade nos casos resolvidos pelo Poder Judiciário. A teoria adaptada do sistema de common law pretende dar um peso especial às decisões judiciais e os argumentos jurídicos nela utilizados.

Ou seja, os precedentes judiciais foram uma resposta do legislador no caminho de assegurar um direito mais coeso.

A conjuntura identificada despertou inúmeras vozes no sentido da busca de um caminho alternativo àquele quadro caótico apresentado, pois, no âmbito jurisprudencial, o dissídio não seria salutar como em outras fontes do direito, especialmente na doutrina, devendo ser combatido. A sensação de loteria judiciária seria inevitável quando os jurisdicionados recebem tratamento díspare diante de situações idênticas, o que inexoravelmente dificulta o cumprimento espontâneo dos julgados. Decisões heterogêneas passam a ser personalizadas e associadas ao juiz que as proferiu e às partes nela envolvidas. O respeito aos precedentes despersonaliza as demandas e cria um espaço de aceitação das decisões e de afirmação do poder estatal, especialmente diante do respeito ao passado, além de racionalizar o duplo grau de jurisdição, contribuir à duração razoável do processo (grande parte das questões já estão maturadas e decididas), controlar o poder do juiz e sua necessária imparcialidade, assegurar coerência, isonomia e segurança jurídica, desestimular a litigância e favorecer acordos diante da predefinição de expectativas ${ }^{49}$.

O legislador previu um rol de precedentes obrigatórios, criando uma nova sistemática de vinculação vertical entre órgãos judiciários. O artigo 927 introduziu um grande número de precedentes vinculantes no sistema brasileiro, além das decisões proferidas em controle concentrado da constitucionalidade e das súmulas vinculantes, que já possuíam essa eficácia no código anterior, o

49 RAMOS, Carlos Henrique; MOUSINHO, Isabel Ribeiro. O novo Código de Processo Civil e o sistema de precedentes vinculantes. Revista Brasileira de Direito Processual - RBDPro, Belo Horizonte, ano 25, n. 98, abr./jun. 2017. p. 61. 
CRUZ, Paulo Márcio; BARBIERO, Victória Faria. Aspectos gerais dos precedentes judiciais e a dogmática do novo código de processo civil. Revista Eletrônica Direito e Política, Programa de PósGraduação Stricto Sensu em Ciência Jurídica da UNIVALI, Itajaí, v.15, n.3, 30 quadrimestre de 2020. Disponível em: www.univali.br/direitoepolitica - ISSN 1980-7791

novo código atribuiu efeitos vinculantes: aos acórdãos em incidente de assunção de competência ou de resolução de demandas repetitivas e em julgamento de recursos extraordinário e especial repetitivos; aos enunciados das súmulas do Supremo Tribunal Federal em matéria constitucional e do Superior Tribunal de Justiça em matéria infraconstitucional; a orientação do plenário ou do órgão especial aos quais estiverem vinculados. Os precedentes proferidos nestes casos deverão ser obrigatoriamente observados pelos juízes ${ }^{50}$.

Já o artigo 489 prolata que não se considera fundamentada a decisão que, dentre outras opções, se limita a invocar precedente ou enunciado de súmula, sem identificar seus fundamentos determinantes nem demonstrar que o caso em julgamento se ajusta àqueles fundamentos ou deixa de seguir enunciado de súmula, jurisprudência ou precedente invocado pela parte, não demonstrando a existência de distinção no caso em julgamento ou a superação do entendimento ${ }^{51}$.

Nogueira ${ }^{52}$ faz uma interessante observação quanto ao novo papel do juiz nesse processo. Assim,

a admissão de um regime de precedentes concretiza uma nova fase do direito processual, onde os resultados obtidos no processo são qualificados por não se esgotarem nos limites da lide. O processo passa a ser valorizado como espaço de criação do direito pelo Estado-juiz, de participação democrática da sociedade e de vivência da norma. É meio de desenvolvimento do direito material, o que é expresso mediante os precedentes oriundos da atividade jurisdicional.

O eixo central desta discussão é o olhar por novas formas de raciocinar o direito, pois se altera o método de análise jurídica. O sistema jurídico brasileiro se encontra em um processo de inserção de nova técnica vinculante da decisão judicial, técnica esta que é originária de uma tradição de direito distinta da civil law, e que causa um certo estranhamento por parte de doutrinadores.

50 BRASIL. Lei no 13.105, de 16 de março de 2015. Código de Processo Civil. Disponível em: http://www.planalto.gov.br/ccivil_03/_ato2015-2018/2015/lei//13105.htm. Acesso em: mai. 2020.

${ }^{51}$ BRASIL. Lei no 13.105, de 16 de março de 2015. Código de Processo Civil.

52 NOGUEIRA, Cláudia Albagli. O Novo Código de Processo Civil e o sistema de precedentes judiciais: pensando um paradigma discursivo da decisão judicial. Revista Brasileira de Direito Processual - RBDPro, Belo Horizonte, ano 22, n. 88, out./dez. 2014. Disponível em: <http://www.bidforum.com.br/PDI0006.aspx?pdiCntd=213410>. Acesso em: 28 nov. 2019. 
CRUZ, Paulo Márcio; BARBIERO, Victória Faria. Aspectos gerais dos precedentes judiciais e a dogmática do novo código de processo civil. Revista Eletrônica Direito e Política, Programa de PósGraduação Stricto Sensu em Ciência Jurídica da UNIVALI, Itajaí, v.15, n.3, 30 quadrimestre de 2020. Disponível em: www.univali.br/direitoepolitica - ISSN 1980-7791

Porém, a percepção inicial seria atender as situações que são chamadas de casos difíceis, processos em que não se encontra a resolução a partir de apenas a aplicação de regra ${ }^{53}$.

Como consequência imediata, está a exigência de uma maior carga argumentativa, pois, se estamos a falar da excepcionalidade, que é a não aplicação da regra, pela sua superação ou pela sobreposição de um princípio, indispensável que estejam fartamente expressas as razões para a alternativa por outro sistema de decisão judicial, sendo o mais comumente apontado a técnica de ponderação. 9 Cabe ao juiz o compromisso com a densidade argumentativa que demonstre a plausibilidade e resguarde a racionalidade da decisão judicial ${ }^{54}$.

Ademais, não se pode deixar de salientar a importância do precedente judicial a fim de consagrar uma maior segurança jurídica no judiciário brasileiro. 0 precedente judicial se torna um importante instrumento dentro do Poder Judiciário, pois altera a sistemática da matriz processual do direito brasileiro.

No contexto já explanado, incumbe ao direito e, por consequência, à jurisdição, a tarefa de qualificar axiologicamente o agir humano não apenas na perspectiva do comportamento responsável intersubjetivo e comunitário, mas também como um compromisso ético alargado, exercido em longo prazo, tanto em benefício e atenção das futuras gerações como também de toda a comunidade de vida.

A sustentabilidade, em sua acepção mais ampla, será, se já não é, o principal item de debate no panorama jurídico. O capitalismo predatório afogou todas as estruturas, sejam sociais ou ambientais, e "a preservação e a recuperação do ambiente e sua utilização racional sugerem a reinvenção da tensão entre direito e liberalismo capitalista, o que poderá gerar a necessária sustentabilidade ${ }^{55 ",}$ inclusive na própria estrutura do Direito. Assim, tanto o ativismo judicial como os precedentes vinculantes tornam o campo de atuação da hermenêutica judiciária, do instrumento processo, mais sustentável. Procuram construir um panorama

\footnotetext{
53 NOGUEIRA, Cláudia Albagli. O Novo Código de Processo Civil e o sistema de precedentes judiciais: pensando um paradigma discursivo da decisão judicial. p. 4.

${ }^{54}$ NOGUEIRA, Cláudia Albagli. O Novo Código de Processo Civil e o sistema de precedentes judiciais: pensando um paradigma discursivo da decisão judicial. p. 4.

55 BODNAR, Zenildo; CRUZ, Paulo Márcio. A commolização do direito positivo, o ativismo judicial e a crise do estado. p. 1346-1347.
} 
CRUZ, Paulo Márcio; BARBIERO, Victória Faria. Aspectos gerais dos precedentes judiciais e a dogmática do novo código de processo civil. Revista Eletrônica Direito e Política, Programa de PósGraduação Stricto Sensu em Ciência Jurídica da UNIVALI, Itajaí, v.15, n.3, 30 quadrimestre de 2020. Disponível em: www.univali.br/direitoepolitica - ISSN 1980-7791

sustentável e equilibrado para um judiciário afogado com novas demandas hipercomplexas e decisões contraditórias, reservando até mesmo, para si, a preservação do espaço que o direito ocupa nessa sociedade, por meio da segurança jurídica.

Portanto, aos poucos o Poder judiciário também foi se reformulando em meio ao caos e às crises existentes nesse sistema predatório. Incumbe aos juristas, nesse momento, repensar também suas práticas, seja na advocacia ou na formulação do conhecimento jurídico, a fim de enquadrarmos um direito que possa resolver às lides hipercomplexas ou em massa, de forma mais ágil e estável.

\section{CONSIDERAÇÕES FINAIS}

As aceleradas mudanças da sociedade nos últimos tempos originou a necessidade de repensar o Estado e o direito moderno. As novas teorizações acerca da aplicação do direito representa uma possibilidade de respostas mais apropriadas para as novas e complexas demandas, como, por exemplo, no momento em que o Poder Judiciário passa a atuar em âmbitos antes reservados aos poderes executivo e legislativo, por meio do ativismo judicial.

Nesse ponto, o código civil brasileiro incorpora o precedente judicial vinculante, procurando fazer o processo civil mais eficiente, rápido e seguro, já que pretende dar respostas mais rápidas às maiores complexidades e demandas do século XXI. Decorrente de uma família de direitos distinta da brasileira, o precedente também expressa a cultura de segurança e estabilidade do povo inglês. Por isso, a construção da confiança no juiz demostra a necessidade de afastamento de uma dogmática escrita e deposita no Clero ou na consciência do monarca. A Inglaterra sempre foi conhecida por se portar de forma mais pragmática e investir em instituições bem segmentadas. Assim, é importante estudar como se estruturou a common law no passar dos anos para entender como se insere os precedentes nesse sistema.

Quando se fala exclusivamente na hermenêutica dos precedentes na common law, a teoria do stare decisis surge como o ponto nevrálgico do trabalho em questão: significa dizer que as decisões anteriores já resolvidas por um juízo não 
CRUZ, Paulo Márcio; BARBIERO, Victória Faria. Aspectos gerais dos precedentes judiciais e a dogmática do novo código de processo civil. Revista Eletrônica Direito e Política, Programa de PósGraduação Stricto Sensu em Ciência Jurídica da UNIVALI, Itajaí, v.15, n.3, 30 quadrimestre de 2020. Disponível em: www.univali.br/direitoepolitica - ISSN 1980-7791

podem ser desconsideradas, e advém com a intenção de afirmar às relações jurídicas resolvidas e as novas, atribuindo-lhes igualdade e coerência do direito. Isso só é possível com um procedimento bem fundamentado e desenvolvido ao longo do tempo, como o presente trabalho apresentou.

No Brasil, a intenção do legislador também é promover decisões mais coesas e coerentes entre os diversos juízos e graus de jurisdição. Para tanto, existem novos espaços e argumentações que o judiciário deverá compreender para que esse instrumento seja corretamente utilizado. Surgem novos espaços de discussão que serão ocupados principalmente pela doutrina e pelos juízes. Assim, apenas como o uso e a prática dos precedentes que poderá ser realizada a análise da efetividade dessa medida na dogmática processual como um todo, a fim de um judiciário mais sustentável.

\section{REFERÊNCIAS DAS FONTES CITADAS}

ABBOUD, Georges. STRECK, Lenio Luiz. O Que é Isto?: O Precedente Judicial e as Súmulas Vinculantes. São Paulo: Livraria do Advogado Editora, 2015.

BARBOZA, Estefânia Maria de Queiroz. Precedentes judiciais e segurança jurídica: fundamentos e possibilidades para a jurisdição constitucional brasileira. São Paulo: Editora Saraiva, 2014.

BODNAR, Zenildo; CRUZ, Paulo Márcio. A commolização do direito positivo, o ativismo judicial e a crise do estado. Novos Estudos Jurídicos, v. 21, n. 3, p. $1332-1351,2016$.

BRASIL. Lei no 13.105, de 16 de março de 2015. Código de Processo Civil. Disponível em: http://www.planalto.gov.br/ccivil_03/_ato20152018/2015/lei/l13105.htm. Acesso em: mai. 2020.

DAVID, René. Os grandes sistemas do direito contemporâneo. São Paulo: Martins Fontes, 2002.

DUXBURY, Neil. The nature and authority of precedent. Cambridge University Press, 2008.

GOODHART, Arthur L. Determining the ratio decidendi of a case. Yale Lj, v. 40, p. 161, 1930.

MARINONI, Luiz Guilherme. Aproximação crítica entre as jurisdições de civil law e de common law e a necessidade de respeito aos precedentes no Brasil. Revista da Faculdade de Direito UFPR, v. 49, p. 11-58. 2009. 
CRUZ, Paulo Márcio; BARBIERO, Victória Faria. Aspectos gerais dos precedentes judiciais e a dogmática do novo código de processo civil. Revista Eletrônica Direito e Política, Programa de PósGraduação Stricto Sensu em Ciência Jurídica da UNIVALI, Itajaí, v.15, n.3, 30 quadrimestre de 2020. Disponível em: www.univali.br/direitoepolitica - ISSN 1980-7791

MARINONI, Luiz Guilherme. Precedentes Obrigatórios. São Paulo: Revista dos Tribunais, 2016.

MELLO, Patrícia Perrone Campos; BARROSO, Luís Roberto. Trabalhando com uma nova lógica: a ascensão dos precedentes no direito brasileiro. Revista da AGU, v. 15, n. 3, p. 9-52, 2016.

NOGUEIRA, Cláudia Albagli. O Novo Código de Processo Civil e o sistema de precedentes judiciais: pensando um paradigma discursivo da decisão judicial. Revista Brasileira de Direito Processual - RBDPro, Belo Horizonte, ano 22, n. 88, out./dez. $2014 . \quad$ Disponível em: <http://www.bidforum.com.br/PDI0006.aspx?pdiCntd=213410>. Acesso em: 28 nov. 2019

PORTO, Sérgio Gilberto. Sobre a common law, civil law e o precedente judicial: estudos de Direito Processual Civil em homenagem ao Professor Egas Dirceu Moniz de Aragão. São Paulo: RT, 2005.

RADBRUCH, Gustav. O espírito do direito inglês e a jurisprudência AngloAmericana. Rio de Janeiro: Lumen Juris, 2010.

RAMIRES, Mauricio. Crítica à aplicação de precedentes no direito brasileiro. Porto Alegre: Livraria do Advogado, 2010. p.73.

RAMOS, Carlos Henrique; MOUSINHO, Isabel Ribeiro. O novo Código de Processo Civil e o sistema de precedentes vinculantes. Revista Brasileira de Direito Processual - RBDPro, Belo Horizonte, ano 25, n. 98, abr./jun. 2017. Disponível em: <http://www.bidforum.com.br/PDI0006.aspx?pdiCntd=247546>. Acesso em: 28 nov. 2019.

SCHAUER, Frederick. Thinking like a lawyer: a new introduction to legal reasoning. Boston: Harvard University Press, 2009.

SOARES, Guido Fernando Silva. Common law: introdução ao direito dos EUA. São Paulo: Revista dos Tribunais, 1999.

VENOSA, Sílvio de Salvo. Direito civil: parte geral. 3. ed. São Paulo: Atlas, 2003. 